\title{
Access by general practitioners to physiotherapy department of a district general hospital
}

\author{
P NORMAN, H CLIFTON, E WILLIAMS, P J R NICHOLS
}

British Medical fournal, 1975, 4, 220-221

\section{Summary}

There has been much opposition, voiced most notably in the Tunbridge Report, to general-practitioner access to hospital rehabilitation services. Co-operation between general practitioners, physiotherapists, and the consultant with responsibility for the physiotherapy department at a general district hospital has provided an efficient open-access service. This service has been welcomed by the general practitioners because it supplies prompt treatment for their patients and by the physiotherapists because it enables them to minimise disability by treating musculoskeletal problems at an early stage.

\section{Introduction}

Recent discussions on the future role of physiotherapy have often centred on an expansion of the therapist's activities. Many proposals have been put forward, but two in particular-direct general-practitioner referral to a hospital department (openaccess physiotherapy), and the attachment of a physiotherapist to the primary care team (domiciliary physiotherapy)-have engendered most debate. ${ }^{12}$ We describe here the experience gained from the operation of a physiotherapy department on open-access principles.

\section{Physiotherapy services at the district general hospital}

The Horton General Hospital at Banbury is a district general hospital with 212 beds serving a population of 100000 people within a 10-mile radius. This catchment area includes North Oxfordshire and the adjacent portions of Warwickshire and Northamptonshire. Outpatient clinics are held in general medicine, neurology, dermatology, rheumatology, physical medicine, general surgery, orthopaedics, otorhinolaryngology, gynaecology, and radiotherapy and are staffed by consultants from Banbury and Oxford. Furthermore, there is an active geriatric service based on a 32-bed unit, the Neithrop Hospital at Banbury, and there are three small outlying community hospitals where physiotherapy services are under the supervision of another consultant physician.

\footnotetext{
Oxford Rehabilitation Research Unit, Mary Marlborough Lodge, Nuffield Orthopaedic Centre, Headington, Oxford OX3 7LD

P NORMAN, MCSP, research physiotherapist, Oxford Rehabilitation Research Unit

H CLIFTON, MCSP, research physiotherapist, Oxford Rehabilitation Research Unit

E WILLIAMS, MB, MRCP, senior registrar, Mary Marlborough Lodge

P J R NICHOLS, DM, FRCP, director, Mary Marlborough Lodge and Oxford Rehabilitation Research Unit
}

About 50 general practitioners practise in the area served by Horton General Hospital, and over half of these refer patients directly to its physiotherapy department, the remainder finding it more convenient to refer patients to the outlying community hospitals.

At Horton General Hospital the physiotherapy establishment is full and consists of one superintendent physiotherapist (whole time), two physiotherapists (whole time), and one part-time helper working on the wards, with five part-time physiotherapists (two whole-time equivalents) and one part time helper working in the outpatient department. Careful organisation of the five part-time physiotherapists has resulted in an adequately staffed department capable of providing a five-day outpatient service with no waiting list for treatment.

At the Neithrop Hospital (for which physiotherapy services are arranged from the department at the Horton General Hospital) there is one part-time senior physiotherapist and four part-time physiotherapists (one whole-time equivalent), with two part time helpers. These members of staff work under the direction of the physicians to the geriatric service but overall responsibility for both departments is vested in an Oxford-based consultant physician.

DEPARTMENT POLICY

Until 10 years ago the Banbury hospitals were staffed largely by general practitioners on a part-time basis. When hospital-based consultant staff began to be appointed it was natural that patterns of care that had worked well should be retained. The new consultant with responsibility for physiotherapy services was happy to continue with the existing open-access system-a system that has now operated under his supervision for 10 years. Referrals from general practitioners, consultant outpatient clinics, and medical staff providing inpatient care continue to be accepted directly by the physiotherapists.

General practitioners referring patients to the department send a letter of referral to the superintendent, though this may, if the case is urgent, be preceded by a telephone conversation. In such cases the patient will be assessed within hours of the general practitioner's telephone call, but all patients are assessed and have their treatment started within one week of referral. If the superintendent physiotherapist is concerned about any matter, whether diagnosis, treatment, or the progress of a patient referred from general practice, she will discuss the problem by telephone with the doctor concerned. A decision can then be made on whether the patient should be reviewed at the general practitioner's surgery or whether he should be referred to the consultant's next weekly clinic. Whenever the therapists are concerned about the diagnosis, prognosis, or recommended treatment and are unable to obtain an urgent review by the referring doctor the consultant in charge of physiotherapy services has reserved the right to assess any patient attending the department. Furthermore, no patient referred by any doctor is treated for more than six weeks without the consent of the consultant in charge of the department.

To maintain appropriate standards of physiotherapy and to avoid requests for purely palliative and ineffectual treatments the practical management of conditions commonly referred to the outpatient department has been delineated. Priority is given to recent injuries, to any exacerbation of arthritis, and to the care of children. Patterns of management for common problems such as backache and neckache are standardised. Requests for aids and equipment are dealt with directly by the superintendent physiotherapist, with urgent requirements being supplied from stock.

Docto-s practising in the hospital's catchment area have come to 
learn and accept that effective physiotherapy can best be provided if they supply the therapist with adequate clinical information and guidelines for treatment. The therapist is allowed, if necessary, to adapt these guidelines to the requirements of each patient in the light of her own experience and within the limits of the departmental policies.

\section{Study of the service}

Outpatient workload - We studied the outpatient work load over the five years 1970-4, a period during which the staffing of the department remained constant and a period sufficiently recent to portray the current patterns of referral while still enabling us to detect any variations from year to year. We looked specifically at the months of February and June: February because it was a winter month and yet not disrupted by a bank holiday and June because it was a summer month before the school summer holidays (table I). Comparable numbers of patients were referred to the department each year and the source of these referrals is shown in table II. Table III subdivides the work load from the two major sources of referral-the orthopaedic clinic (excluding the fracture service) and general practice-according to the presenting problems. There was a significant difference in the types of problems referred, general-practitioner referrals including a higher proportion of degenerative musculoskeletal problems.

General practitioners' reactions-The 30 general practitioners who use the open-access service were invited to give their views on its efficacy and its use to them and their patients. Twenty-nine replied and all were enthusiastic supporters of the scheme. Comments such as, "This is a valuable service which I should hate to lose, and I therefore make every attempt not to over use it"; "It is of great benefit to both patient and doctor that treatment can be obtained so quickly"; and, "No doubt this is in turn lessening the work load of consultant clinics" were frequently received. Several of the general practitioners emphasised that they tried deliberately not to over use the service for they realised that to do so might prove detrimental. This is confirmed by the data in table I, which show that over the period studied the referrals emanating from general practice varied from $19 \%$ to $30 \%$ of the outpatient work load-an average of $24 \%$.

TABLE I-Numbers of outpatients referred to physiotherapy department at Horton General Hospital during February and fune 1970-4

\begin{tabular}{l|r|r|r|r|r|r}
\hline & 1970 & 1971 & 1972 & 1973 & 1974 & Total \\
\hline $\begin{array}{l}\text { February } \\
\text { June }\end{array}$ & 146 & 181 & 166 & 167 & 159 & 819 \\
\hline Total & 298 & 337 & 312 & 302 & 310 & 1559 \\
\hline
\end{tabular}

\section{Discussion}

The Tunbridge Report claimed that "many general practitioners are out of touch with modern concepts of remedial treatment" and it suggested that if open-access physiotherapy was provided "departments might become overburdened with patients for whom unnecessary or inadequate treatment had been prescribed." 3 This statement embodies two suppositions: firstly, that a general practitioner needs detailed knowledge of the modern concepts of remedial treatment and, secondly, that he should prescribe treatment.

We have found that experienced physiotherapists working with an adequate diagnosis and with guidelines delineating the aims of treatment are capable of managing or modifying the details of a patient's treatment within the confines of their experience and within the policies of their department. Such a service can be provided without hazard to the patient only if the therapists are experienced and if they are able to communicate readily with the referring doctor. This is especially important in the early stages of musculoskeletal disorders, when descriptive diagnoses such as "painful shoulder" or "backache" may be most appropriate. If improvement and a return of function does not follow the start of treatment in such conditions the physiotherapist must always discuss the patient with the referring doctor or, if he is not available, the consultant physician in charge of the department. Thus the patient, the physiotherapist, and the referring doctor are safeguarded and yet all enjoy great advantages from the scheme. The patient obtains physiotherapy at an early stage with the chance of minimising the disability; the therapist treats patients who because of the recent onset of symptoms may have somewhat imprecise diagnoses, circumstances in which she must be especially watchful; and the general practitioner enjoys far greater contact with the hospital rehablitation services.

Conclusions-The physiotherapy department at Horton General Hospital, Banbury, works well on open-access principles. Limited resources are used to greatest advantage to maintain a prompt assessment and treatment service, which relies heavily on the competence of the therapists and their adherence to departmental policy. Such a service is not only of great help to general practitioners and their patients but may also be expected to reduce the pressure on hospital-based outpatient clinics.

We acknowledge the help and enthusiasm shown by the general practitioners and hospital staff at the Horton General Hospital, Banbury. In particular we thank Mrs $\mathrm{H}$ Held, superintendent physiotherapist at Horton General Hospital, for her assistance during this study.

\section{References}

1 Department of Health and Social Security, The Remedial Professions, para 38. London, HMSO, 1973. (McMillan Report).

2 Department of Health and Social Security and Welsh Office, The Organisation of Group Practice. London, HMSO, 1972 (Davis Report.)

${ }^{3}$ Department of Health and Social Security, Rehabilitation. A report of a subcommittee of the Standing Medical Advisory Committee. London, HMSO, 1972. (Tunbridge Report.)

TABLE II-Percentages of patients referred for outpatient physiotherapy from sources during periods studied

\begin{tabular}{|c|c|c|c|c|c|c|c|c|c|c|c|}
\hline & $\begin{array}{l}1970 \\
\text { Feb }\end{array}$ & $\begin{array}{c}1970 \\
\text { Jun }\end{array}$ & $\begin{array}{c}1971 \\
\text { Feb }\end{array}$ & $\begin{array}{c}1971 \\
\text { Jun }\end{array}$ & $\begin{array}{c}1972 \\
\text { Feb }\end{array}$ & $\begin{array}{c}1972 \\
\text { Jun }\end{array}$ & $\begin{array}{c}1973 \\
\text { Feb }\end{array}$ & $\begin{array}{c}1973 \\
\text { Jun }\end{array}$ & $\begin{array}{c}1974 \\
\text { Feb }\end{array}$ & $\begin{array}{c}1974 \\
\text { Jun }\end{array}$ & Mean \\
\hline $\begin{array}{l}\text { Orthopaedic clinic } \\
\text { General practice } \\
\text { Fracture clinic and casualty } \\
\text { department }\end{array}$ & $\begin{array}{l}38 \\
30 \\
11\end{array}$ & $\begin{array}{l}37 \\
19 \\
22\end{array}$ & $\begin{array}{l}37 \\
19 \\
26\end{array}$ & $\begin{array}{l}44 \\
22 \\
24\end{array}$ & $\begin{array}{l}40 \\
23 \\
19\end{array}$ & $\begin{array}{l}36 \\
27 \\
17\end{array}$ & $\begin{array}{l}27 \\
26 \\
18\end{array}$ & $\begin{array}{l}35 \\
30 \\
13\end{array}$ & $\begin{array}{l}37 \\
23 \\
23\end{array}$ & $\begin{array}{l}45 \\
24 \\
16\end{array}$ & $\begin{array}{l}38 \\
24 \\
19\end{array}$ \\
\hline $\begin{array}{l}\text { Physical medicine clinic } \\
\text { Other }\end{array}$ & $\begin{array}{l}11 \\
10\end{array}$ & $\begin{array}{l}10 \\
12\end{array}$ & $\begin{array}{r}12 \\
6\end{array}$ & $\begin{array}{l}3 \\
7\end{array}$ & $\begin{array}{r}11 \\
7\end{array}$ & $\begin{array}{r}14 \\
6\end{array}$ & $\begin{array}{l}13 \\
16\end{array}$ & $\begin{array}{r}8 \\
14\end{array}$ & $\begin{array}{l}9 \\
8\end{array}$ & $\begin{array}{l}6 \\
9\end{array}$ & $\begin{array}{r}10 \\
9\end{array}$ \\
\hline
\end{tabular}

TABLE III-Problems expressed as percentages of referrals from orthopaedic clinic and general practice to physiotherapy department 1970-4

\begin{tabular}{|c|c|c|c|c|c|c|c|c|c|c|c|c|}
\hline \multirow{2}{*}{ Problems } & \multicolumn{6}{|c|}{ Orthopaedic clinic } & \multicolumn{6}{|c|}{ General practice } \\
\hline & 1970 & 1971 & 1972 & 1973 & 1974 & Mean & 1970 & 1971 & 1972 & 1973 & 1974 & Mean \\
\hline $\begin{array}{l}\text { Degenerative musculo-skeletal disorders } \\
\text { Postoperative mobilisation } \\
\text { Post-trauma mobilisation } \\
\text { Other }\end{array}$ & $\begin{array}{r}40 \\
25 \\
30 \\
5\end{array}$ & $\begin{array}{r}50 \\
26 \\
21 \\
3\end{array}$ & $\begin{aligned} 42 \\
37 \\
19 \\
2\end{aligned}$ & $\begin{array}{r}44 \\
23 \\
27 \\
6\end{array}$ & $\begin{array}{r}51 \\
18 \\
27 \\
4\end{array}$ & $\begin{array}{r}45 \\
26 \\
25 \\
4\end{array}$ & $\begin{array}{l}70 \\
3 \\
10 \\
17\end{array}$ & $\begin{array}{l}\frac{59}{26} \\
15\end{array}$ & $\begin{array}{r}74 \\
8 \\
3 \\
15\end{array}$ & $\begin{array}{l}69 \\
5 \\
13 \\
13\end{array}$ & $\begin{array}{r}78 \\
2 \\
14 \\
6\end{array}$ & $\begin{array}{l}70 \\
4 \\
13 \\
13\end{array}$ \\
\hline
\end{tabular}

